\title{
HYDROLYSIS OF LEATHER SHAVINGS: MATHEMATICAL MODEL AND EXPERIMENT
}

\author{
Hana Vaskova
}
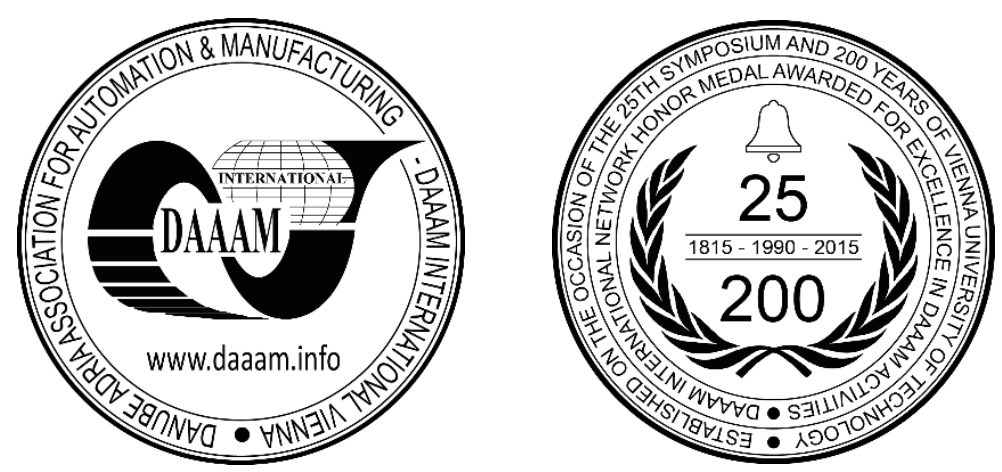

This Publication has to be referred as: Vaskova, H[ana] (2018). Hydrolysis of Leather Shavings: Mathematical Model and Experiment, Proceedings of the 29th DAAAM International Symposium, pp.0338-0340, B. Katalinic (Ed.), Published by DAAAM International, ISBN 978-3-902734-20-4, ISSN 1726-9679, Vienna, Austria

DOI: $10.2507 / 29$ th.daaam.proceedings.048

\begin{abstract}
The paper deals with the mathematical description of the alkaline hydrolysis of leather waste material and the comparison with real experimental data. Leather industry produce large quantities of waste. It is reasonable, both, ecologically and economically, to apply recycling processes for further reduction of the non-recoverable waste amount and reuse what the waste material still offers. The focus of the study is on collagen protein contained in leather shavings. The mathematical model of the collagen hydrolyzate gain is based on the mass and mass fraction of dry matter balances. The gain closely relates to the parameters of input materials and intermediates in the production process. The visualizations of the solutions of balance mathematical model are presented. The data obtained from laboratory experiments indicate slightly lower gains due to insufficient isolation of the reactor used. Therefore, the loss coefficient needs be included in the model to reach higher correlation. The results are discussed in the paper.
\end{abstract}

Keywords: mathematical model; hydrolysis; leather, waste recycling, collagen hydrolyzate

\section{Introduction}

In today's world, people are able to produce enormous quantity of various products. However, each manufacturing means not only the production of the desired output, but also generation of some amount of waste. The environmental aspect related with the waste generation and waste disposal is an important issue to be solved.

The study focuses on the waste arising from the leather industry. Several treatment processes have to be done to convert raw hides into leather. The diversity and amounts of produced waste represent a serious problem. The most common type of hide tanning worldwide is the chrome-tanning. The production of $200 \mathrm{~kg}$ of leather requires $1000 \mathrm{~kg}$ of raw hides, i.e. the effective use of the feedstock is only twenty percent. This conversion represents also production of about $200 \mathrm{~kg}$ of non-tanned waste and about $200 \mathrm{~kg}$ of tanned wastes containing chromium [1]. A remaining share comprises modified solid waste and sludge. The production of $200 \mathrm{~kg}$ of leather generates about $50,000 \mathrm{~kg}$ of waste water containing about $5 \mathrm{~kg}$ of chromium [2]. Salts of trivalent chromium (CrIII) stabilize a hide by crosslinking collagen fibres and supply required qualities. Trivalent form of chromium is safe and largely beneficial [3]. However, some amounts of CrIII contained in leather can be during some of the chemical processes oxidized to hexavalent chromium [4]. Hexavalent form of chromium is one of known toxic elements and its salts are classified as carcinogen. 
Therefore, the issue of hexavalent chromium is important from the point of view of safety preservation for workers, users of the product and the environment. The demand for alternative methods of tanning lasts, and there are some existing [5]. None of these methods has the potential for competitive replacement of chrome-tanning, that is used in such a large extend [6]. A partial solution is processing of some kinds of waste material. A separation of collagenous share from chromium part of waste can be reached by hydrolysis in alkaline or acidic conditions. A products as gelatin or protein hydrolysates obtained after further physico-chemical treatment can find cost-effective applications e.g. in food industry, cosmetics or agriculture. The waste material does not always have the same properties and quality. Therefore, mathematic modeling of the treatment is very important for the prediction and analysis of appropriate way of efficient processing of waste.

\section{Mathematical model}

The mathematical model of hydrolyzate gain is based on mass and dry matter balances, which can describe the physical and chemical processes of the hydrolytic reaction. The aim is to reach the maximum gain while maintaining economic advantage, considering the main operating costs. The model of the main operating costs is presented in [7]. The leather waste processing, the production system and mathematical model for automated control implementation are presented in [8]. The physical quantities used in the model are listed in Table 1. Mass fractions of the dry matters are modelled for an interval of values, which are chosen within the ranges that are likely to be achieved during hydrolytic treatment and further steps of the process. Appropriate ratios of feedstock and reagents are based on experience with previous experiments in laboratory and semi-industrial scale. Mass of water, filtrate, filter cake and product are the modelled quantities.

\begin{tabular}{|c|c|c|c|}
\hline Symbol & Physical quantity & Unit & Values - model \\
\hline$m_{s}$ & Mass of shavings & $\mathrm{t}$ & 3 \\
\hline$a_{s}$ & Dry matter of shavings & 1 & $0,20-0,80$ \\
\hline$m_{v}$ & Mass of water & $\mathrm{t}$ & Modelled value \\
\hline$m_{o}$ & Mass of organic base & $\mathrm{t}$ & - \\
\hline$m_{m}$ & Mass of MgO & $\mathrm{t}$ & - \\
\hline$m_{f}$ & Mass of filtrate & $\mathrm{t}$ & Modelled value \\
\hline$a_{f}$ & Dry matter of filtrate & 1 & 0,02 \\
\hline$m_{c}$ & Mass of filter cake & $\mathrm{t}$ & Modelled value \\
\hline$a_{c}$ & Dry matter of filter cake & 1 & $0,1-0,5$ \\
\hline$m_{w}$ & Mass of waste water & $\mathrm{t}$ & - \\
\hline$m_{p}$ & Mass of product & $\mathrm{t}$ & Modelled value \\
\hline$a_{p}$ & Dry matter of product & 1 & 0,3 \\
\hline
\end{tabular}

Table 1. The physical quantities and values of feedstock, intermediates and products for the model

Equations (1) and (2) describe the mentioned balances for the whole technology consisting of reactor, filter and evaporator; equation (3) describes reactor and filter balance (3), for evaporator it is equation (4).

$$
\begin{aligned}
& m_{s}+m_{v}+m_{o}+m_{m}=m_{c}+m_{p}+m_{w} \\
& a_{s} m_{s}+m_{m}=a_{c} m_{c}+a_{p} m_{p} \\
& m_{s}+m_{v}+m_{o}+m_{m}=m_{f}+m_{c} \\
& a_{c} m_{c}=a_{p} m_{p}+a_{c} m_{p}
\end{aligned}
$$

\subsection{Result Visualization}

Equations (1) - (4) were used for the modeling and visualisation of the results. Fig. 1 shows the effect of dry matter of shavings and dry matter of filter cake on mass of the product. The time of filtration and the consumption of pressure energy affects the final value of dry matter of filter cake. The hydrolysis process is effective to reach the value of dry matter of filter cake approximately 0,3 as shown in Fig. 1. Longer time of the hydrolysis reaction means only a slight increase of the mass of the product which is due to higher energy consumption undesirable from the point of view of the calculation of operating costs [7]. The effect of dry matter of filter cake and mass of water for three specific dry matter values of the leather shavings $0,2,0,5$ and 0,8 on mass of hydrolyzate and product mass dependence on dry matter of shavings and water consumption was also dealt. 


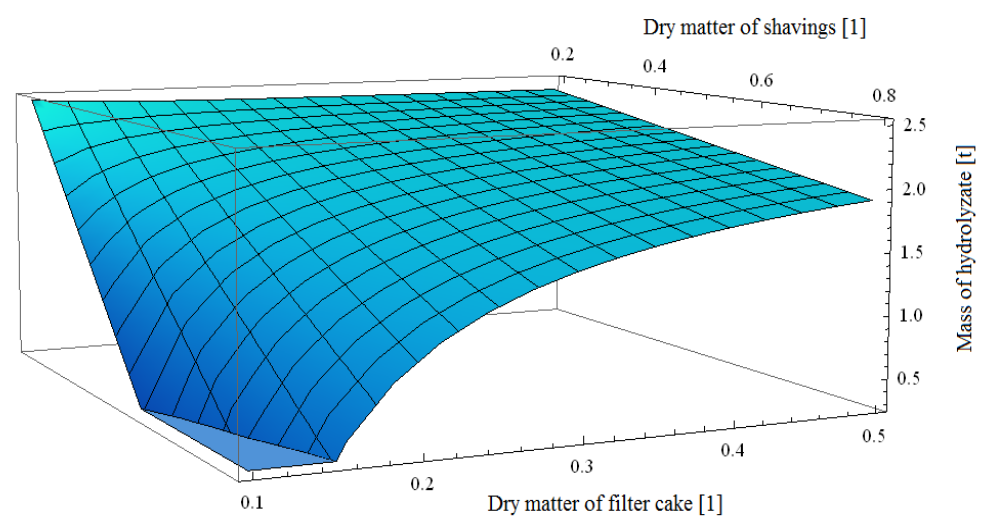

Fig. 1. Dependence of mass of the hydrolyzate (the product) on dry matter shavings and dry matter of filter cake

\section{Experimental hydrolysis}

A laboratory data of two experiments were used for the comparison with the model. A hydrolysis reaction took place in automatically controlled batch reactor and was followed by a filtration through a fabric filter. The collagen hydrolyzate and a filter cake were obtained.

The feedstock ratio for shavings to water was in both cases 1 to $5,(2 \mathrm{~kg}+10 \mathrm{~kg}$, and $3 \mathrm{~kg}+15 \mathrm{~kg})$ as successfully tested in previous experiments. Addition of $\mathrm{MgO}$ ensured the optimal alkaline conditions. Alkalinization took 2 days, the mixture was heated up to $70{ }^{\circ} \mathrm{C}$ then, Alcalase enzyme was added. Hydrolysis reaction took 4 hours and was finished by filtration. Dry matters of shavings were 0,64 and 0,37. Total chromium measured in both cases in feedstock was comparable: 33,70 and $33,74 \mathrm{~g} / \mathrm{kg}$ of dry matter. Masses of filter cake were $6,12 \mathrm{~kg}$ and $6,04 \mathrm{~kg}$; dry matters of filter cake were the same 0,18. Amounts of obtained filtrate varied significantly; $4,98 \mathrm{~kg}$ and 0,02 , and $10,10 \mathrm{~kg}$ and 0,02 .

\section{Conclusion}

The study was focused on modeling the gain of collagen hydrolyzate from the leather shavings, a kind of leather waste material, taking into account equilibrium equations describing the physico-chemical behavior of the hydrolysis reaction. The aim was to reduce quantity of waste effectively with minimal operational cost. The comparison of the modeled data with the real experimental results indicated lower filtrate gain than predicted, due to energy losses manifested by a difference in the mass balances of input and output substances up to $10 \%$. Mass losses were most likely caused by water evaporation in real reactor with imperfect isolation. Energy losses calculated on the difference of the amount of the filtrate obtained by model and experiment, reached in both cases $15 \%$. Therefore, it is needful for further, more accurate modeling to include the energy loss in the model, e.g. in form of water evaporation coefficient.

\section{Acknowledgments}

This work was supported by the Ministry of Education, Youth and Sports of the Czech Republic within the National Sustainability Programme project No. LO1303 (MSMT-7778/2014).

\section{References}

[1] Vaskova, H. (2015). Modeling of chemical reactor for leather waste dechromation. Ph.D. Dissertation, Tomas Bata Univerzity in Zlin, Czech Republic

[2] Janacova, D., Vasek, V., Kolomaznik K. et. al. (2010). Optimalizace recyklačních technologií, Automatizace, regulace a procesy, pp. 55-66

[3] Zhang, Xu-Hui, et al. (2011). Chronic occupational exposure to hexavalent chromium causes DNA damage in electroplating workers. BMC Public Health, pp. 224-232, Vol. 11, No. 224.

[4] Kolomaznik, K. et al. (2008). Leather waste - potential threat to human health, and a new technology of its treatment. Journal of Hazardous materials, Vol. 160, No. 2-3, pp. 514-520

[5] Crudu, M. et al. (2014). Valorization of titanium metal wastes as tanning agent used in leather industry. Waste management, Vol. 34, No. 10, pp. 1806-1814.

[6] Proposal for a restriction. Danish Environmental Protection Agency [online] (2012)

[7] Vaskova, H. \& Vasek, V. (2016). Mathematical model of hydrolysis reaction for the collagen hydrolyzate production from leather shavings, Proceedings of the 27th DAAAM International Symposium, pp.271-274 DAAAM International, ISBN 978-3-902734-08-2, Vienna, Austria.

[8] Vaskova, Hana, and Karel Kolomazník. (2017). Modeling the operating costs for production of the hydrolyzate. International Conference on Applied Physics, System Science and Computers. Springer, Cham. 